Senarathna, D.R. and Perera, B.L.S.H., 2021. Managing concrete wastes by implementing contemporary construction practices in Sri Lanka. In: Sandanayake, Y.G., Gunatilake, S. and Waidyasekara, K.G.A.S. (eds). Proceedings of the $9^{\text {th }}$ World Construction Symposium, 9-10 July 2021, Sri Lanka. [Online]. pp. 413-421. DOI: https://doi.org/10.31705/WCS.2021.36. Available from: https://ciobwcs.com/papers/

\title{
MANAGING CONCRETE WASTES BY IMPLEMENTING CONTEMPORARY CONSTRUCTION PRACTICES IN SRI LANKA
}

\author{
D.R. Senarathna ${ }^{1}$ and B.L.S.H. Perera ${ }^{2}$
}

\begin{abstract}
Material waste is one of the main reasons for the client to suffer due to increments in unnecessary costs. Among all construction material wastes, concrete waste highly draws expenses to the project stakeholders. As a main component in construction, the volume of the concrete waste in Sri Lankan construction projects are considerably high, when comparing with the other material wastes. Currently, most of the countries are moving towards the sustainable developments while minimizing concrete waste. Therefore, applying traditional practices to minimize concrete waste have not been successful over the years. The aim of this research study is, to minimize concrete wastes by implementing contemporary practices that assists to reduce the project cost in Sri Lankan construction industry. In order to achieve the aim, comprehensive literature review, a questionnaire survey and semi-structured interviews were conducted to gather data in both qualitative and quantitative procedures. The empirical findings revealed that concrete waste has a positive relationship with the project cost. Same time, discovered the drivers and barriers that gains while implementing contemporary practices in Sri Lanka. Concrete recycling, precast elements, lean construction techniques, value engineering methods and few more other contemporary practices were identified that leads to minimize concrete waste. The results from the interviews found that many projects are willing to implement mentioned contemporary practices within their construction projects although there are few barriers. These findings deliver a valuable evidence to the practitioners with an in-depth understanding about the essential necessity of contemporary practices to construction projects.
\end{abstract}

Keywords: Concrete waste; Construction industry; Contemporary practices; Drivers and barriers; Sri Lanka.

\section{INTRODUCTION}

As a unique field, construction industry comprises of wide range of activities that includes the erection, repair, and demolition of all types of buildings and civil engineering structures. Generally, this industry embraces different types of construction activities that will be carried under namely by "Projects". Project represents a discrete piece of work with a clear start and finish dates, providing specified benefits at the accepted cost (Harris and McCaffer, 2005). To choreograph above mentioned construction activities the involvement of the stakeholders is essential, who are the ones that gain the benefits and have the interest in the final product, by taking part directly or indirectly to complete the project in a successful manner. In order to successfully complete the project, there is the most important factor called as 'Project Characteristics', which need to be considered by the stakeholders. In construction, there are

\footnotetext{
${ }^{1}$ College of Engineering Construction and Living Sciences, Otago Polytechnic, New Zealand, Randima.Senarathna@op.ac.nz

${ }^{2}$ Sanken Overseas (Pvt) Ltd, Sri Lanka, samindi3d@gmail.com
} 
three main project characteristics as Time aspects (speed construction), Cost aspects (level of price), and the Performance (quality of the final product), which are essential to be fulfilled in order to complete the project successfully.

Material, Labour, Plant and Machineries are the main inputs or the resources in the construction project. Both during the construction and demolition creates a large percentage of waste (Richardson et al., 2010). Material waste has been recognized as a major problem in the construction industry. Construction Industry consumes relatively a large volume of material, which has been wasted due to various number of reasons. It can be due to labour attitude towards the material, labour arrangement, and lack of knowledge in reusing the material and the use of new techniques as; value engineering and lean construction techniques within the construction industry. Every year, most of the countries are send these material wastes to landfill instead of being reused and recycled for new construction. To go for the stated aims and targets, it is essential to maintain a proper management within the project for resource handling.

The problem arising out of this waste directly influences the project characteristics. Among this material waste, 'Wasting Concrete' take a great percentage that needs a significant attention. The cost relates to this concrete waste, directly creates an unnecessary expenditure for the Employer's budget. Concrete is used in many ways by most of the countries, which mainly acts as an alternative for the recycled aggregate in construction (Silva et al., 2014). The main problem raised in the concrete waste directly relates to the human behaviour, their attitudes and as well as the arrangement of the work activity. Saunders and Wynn (2004) found that, the attitudes towards the waste minimization among labour and the other contracting parties in the construction is also an issue for this concrete waste. At the same time, Formoso et al., (2002) stated that the deviation in the dimensions of cast-in-place elements (slabs, columns, and beams) and also excessive thickness of slabs is one of the main issues that leads to form concrete waste. These issues are created mainly due to lack of constructability in structural elements, defects in formwork assembling process. Moreover, order additional allowance of concrete due to uncertainty of material consumption within the site, excessive dimensions of concrete foundations will also cause waste of concrete (Formoso et al., 2002). Kazaz et al., (2004) stated that, concrete waste generates at the production of poor-quality concrete with the use of extravagant raw materials. Dosho (2007) documented that, concrete waste accounts roughly 35 million tons per year of the total construction waste due to the demolition and other construction related activities.

Improper design coordination has a huge impact on concrete waste in the construction activities which tends to produce improper, incorrect or un-constructible designs (Zhen et al., 2002). Design change during the construction process is the significant cause of generating waste at the site which occurs due to attitudes of the designer, improperly identifying the client's requirements, and improper detailing of the documents (Kulatunga et al., 2006). Therefore, there is an allowance kept by the estimators for waste at the pre-construction stage of the construction process, but the actual amount gained at the time of execution of the activities are greater than the waste allowance which happens due to less attention and poor forecast on the construction activities at the pre contract stage.

Most of the countries are moving towards the concept of sustainable development while maintaining the balance between the built environments and protecting the natural environment. After wiping out the terrorism issue in 2009, there was a boom in the construction market where most of the projects are moving towards the vertical structures in Sri Lanka. Therefore, these projects are persuading to implement new technologies to minimize the 
construction waste while going for sustainable developments, which continue the developments without compromising the needs for future generation (Zuhairi et al., 2016).

In the past few years, a number of advancements improved in the entire concrete production together with the material recycling, mixture proportion and durability. Also, the new concrete technology is beginning with latest concrete types as, high performance concrete (HPC), ultrahigh-performance concrete and geopolymer concrete which have more advantages when comparing with the standard concrete (Anon, 2010). Most of the construction projects tend to move to use prefabrication concrete elements within both residential and high-rise construction process which generates concrete waste within the site (Zhen et al., 2002). This prefabrication method has been used in the construction for many years which gives more positive benefits in terms of time saving, environmental performance, improve buildability and minimize concrete waste (Shen et al., 2008).

Both developed and developing countries such as Japan, USA, Turkey, and South Korea are the major ready-mix concrete (RMC) producers. Rather than using cast in-situ concrete, they use RMC within their construction projects. It increases the higher productivity, lower costs with higher profits, minimize wastages, increased client's satisfaction, improved competitiveness, and continuous quality development. Kazaz et al. (2004) reported that, the quality production of the ready-mix concrete will solve the problems arising when deficiencies in placing, curing and formwork for the cast in-situ concrete. Ready mix concrete plants ensure the quality of the concrete due to automatic operation compared to manually undertaking.

Current construction industry has focused on applying precast concrete instead of cast in-situ concrete because of a number of various advantages that include less wastage on-site, reduction in site labourers, less volume of building materials, site safety, quick erection, speed in construction and environmental friendliness.

Meanwhile, Sri Lanka is one of many developing countries the use of concrete is very high. Therefore, the construction industry is not very much familiar with new mechanisms / practices. Treloar et al. (2003) documented, a number of researchers have also highlighted, the potential benefits that can be gained by minimizing concrete waste, and also changing the attitudes towards the waste minimization helps to develop the construction process more effectively. The applicability of these practices to Sri Lankan construction industry need to study comprehensively. By reviewing the above, it assists to identify the gap within the research, where there are not any research articles, which address to implement contemporary practices to the context of Sri Lankan construction industry, which to minimize concrete waste towards reducing the project cost.

\section{RESEARCH METHODOLOGY}

The main aim of this research is to minimize concrete waste by implementing contemporary practices in Sri Lankan construction industry.

This research has adopted both qualitative and quantitative procedures as the methods to collect data from both the questionnaire survey and semi-structured interviews from industry experts to evaluate correlations of the factors whilst evaluating the same with the expert opinion. This has given a wider opportunity to ensure the researchers reached to the finest reasons behind the reluctance of contemporary concrete waste management tactics.

Table 1 provides the population and sampling used to gather data. Different disciplines of professions were covered from randomly selected construction projects in Sri Lanka to derive an outcome with content analysis. 
Table 1: Population and sampling

\begin{tabular}{lcc}
\hline Data Collection Method & Population & Sample \\
\hline \multirow{4}{*}{ Questionnaires } & Architect & \\
& Civil Engineer & \\
& Quantity Surveyor & 25 \\
& Project Manager & \\
& Site Engineer & \\
\hline \multirow{3}{*}{ Interviews } & Civil Engineer & \\
& Quantity Surveyor & \\
& Project Manager & 5 \\
& Batching plant operator & \\
& Site Engineer & \\
\hline
\end{tabular}

The questionnaire for this survey was prepared to collect both facts and opinions from the respondents. A web-based questionnaire was designed to collect the data required to test the hypotheses postulated for the study. It contained eight questions where the first four questions were allocated to collect the respondents' demographic data. The rest of the four questions are close ended questions that covered as Likert scale questions (Kulatunga et al., 2006). In order to cover the objectives of the research. Same time, few structured expert interviews had to carry out as face-to-face interviews using open-ended questionnaire technique, which prepared to investigate, the material waste in the Sri Lankan context and factors affecting concrete waste, involvement and current practices taken to minimize concrete waste, drivers and barriers occur when implementing contemporary practices in the Sri Lankan construction industry.

\section{ANALYSIS}

Correlations between sources of concrete waste, contemporary practices and barriers hindering the implementation of contemporary practices towards reducing the project cost have a positive relationship (refer Table 2).

Sources of concrete waste (s), Contemporary practices to reduce the concrete waste (c), Drivers and Barriers hindering the implementation of contemporary practices $(b)$, Project cost $(\mathrm{P})$.

Regression analysis was also applied to identify the impact on the project cost by the concrete waste, as well as by the drivers and barriers which discloses that the relationship between above mentioned (s), (c) and (b) has a positive impact on the project cost (P).

Observed findings showed that, the concrete component is highly used in building and infrastructure construction, and that is one of the major and the most critical element in the concrete structures. In one of a project Civil Engineer stated "there are numerous ways of wasting material at the construction sites by demolition, mixing or ordering excess quantity. Apart from these material waste, there are many ways that lead to generate concrete waste at the very beginning of the construction process". As he told, "mixing concrete manually by the laborers creates a massive waste of concrete. It generates excess quantity of concrete mixed without concern about the quantity required for a specific concrete work. Project manager in another project pointed out "poor coordination in design, procurement, poor material handling, at the time of operation are few causes of concrete waste in construction projects". 
Table 2: Correlation coefficient

\begin{tabular}{|c|c|c|c|c|c|}
\hline \multicolumn{6}{|c|}{ Correlations } \\
\hline & & avgs1 & avge1 & avgb1 & DVP1 \\
\hline \multirow[t]{3}{*}{ avgs1 } & Pearson Correlation & 1 & $.466^{* *}$ & $.503^{* *}$ & $.434^{* *}$ \\
\hline & Sig. (2-tailed) & & .000 & .000 & .001 \\
\hline & $\mathrm{N}$ & 54 & 54 & 54 & 54 \\
\hline \multirow[t]{3}{*}{$\operatorname{avgc1}$} & Pearson Correlation & $.466^{* *}$ & 1 & $.370^{* *}$ & $.298^{*}$ \\
\hline & Sig. (2-tailed) & .000 & & .006 & .029 \\
\hline & $\mathrm{N}$ & 54 & 54 & 54 & 54 \\
\hline \multirow[t]{3}{*}{ avgb1 } & Pearson Correlation & $.503^{* *}$ & $.370^{* *}$ & 1 & $.270^{*}$ \\
\hline & Sig. (2-tailed) & .000 & .006 & & .048 \\
\hline & $\mathrm{N}$ & 54 & 54 & 54 & 54 \\
\hline \multirow[t]{3}{*}{ DVP1 } & Pearson Correlation & $.434^{* *}$ & $.298^{*}$ & $.270^{*}$ & 1 \\
\hline & Sig. (2-tailed) & .001 & .029 & .048 & \\
\hline & $\mathrm{N}$ & 54 & 54 & 54 & 54 \\
\hline
\end{tabular}

** Correlation is significant at the 0.01 level (2-tailed).

${ }^{*}$ Correlation is significant at the 0.05 level (2-tailed).

An Engineer from a leading project emphasized that, "sources of waste are directly or indirectly generated by the attitudes and perception of the labourers who involve in the construction projects". Design changes that create number of variations to the original scope of work, and also improper delivery methods and delivery schedules, improper coordination among the MEP and structural designers are some of highlighted situations that creates concrete waste in construction projects in Sri Lanka.

However, many stakeholders revealed that communication errors were one of the most critical causes to end up concrete in wastes, and apart from that, several causes create concrete waste within the construction activities in a project.

Concrete recycling, using precast concrete elements instead of cast-in-situ concrete, implementing $5 \mathrm{~S}$ which is one of lean construction technique that used to reduce and to manage the material been wastes within the sites, implementing value engineering techniques such as; instead of traditional formwork, using system formwork method, implement post-tensioning technique which needs less concrete volume and few more other techniques currently implemented in some of the construction projects in Sri Lanka. Preparing the 'Material reconciliation report', which compares the difference between the store records and actual requirement of the materials, as the items in the bill of quantities (BOQ) are some contemporary practices that can implement to minimize the concrete waste. Apart from the above, practicing a waste management hierarchy and also conduct training programs and educate the labourers, other professional team members about the new practices and discuss the benefits gain by practicing them, and trying to use concrete recycling within the construction projects will directly affect to minimize concrete waste.

When considering and observing all the findings, the drivers and barriers that create while implementing these new techniques to minimize concrete waste can commonly be gathered to one place as follows: 
Drivers:

- Improve the productivity, reduce unnecessary time and cost, and effectiveness of the material usage

- Reduce the reordering cost and other unnecessary expenses

- Improve the bottom line of the project and bring out the value to the final product

- Enhance the collaboration among the stakeholder in the project

- Increase more employment opportunities in the construction industry

- Changes to drawings will update automatically

- Saving the use of natural materials

Barriers:

- Reluctant to change their usual behaviours

- Affordability of the new machinery to the project made defensive attitudes among the professionals

- Lack of attitudes on workers regarding contemporary technologies

- Lack of confidence in the use of recycled concrete aggregates

- Lack of skilled persons to handle these new contemporary practices are a few barriers that hinder when implementing contemporary practice in Sri Lanka

Both drivers and barriers are states by the stakeholders who are currently employing in the construction industry.

At the same time, every interviewee agreed that implementing contemporary practices are appropriate to reduce the cost of the construction project and also, there are few practices implement currently within the construction projects in Sri Lanka to minimize concrete waste.

The results that analysed from both statistical and content analysis have confirmed that there is a relationship between concrete waste and the project cost in the Sri Lankan construction industry, which is unforeseen and happens out of the stakeholders' control.

When considering the experimental findings gathered and analysed above, it shows the barriers, which employ the contemporary practices in the Sri Lankan construction industry. The above results clearly illustrate the sources of concrete waste, contemporary practices and the drivers and barriers hindering the implementation of contemporary practices that have a positive relationship with the project cost that needs to be administer of being unnecessarily increasing.

\section{DISCUSSION AND CONCLUSIONS}

Construction industry is a complex industry which includes various types of activities carried out by interacting with different parties in various stages. Therefore, it tends to create numerous reasons and instances to generate concrete waste, which takes place out of their control. The amount of concrete wasted in Sri Lankan construction industry, is important when comparing with the other materials wasting from the construction projects in Sri Lanka, due to a number of various reasons. The generation of wasting concrete from the construction activities results in a huge problem due to the solid waste, when considering with the environment and the project cost aspects. Most of the journal articles and research papers reviews the effective ways to minimize concrete waste can by implementing new practices / techniques and concepts. The effective cost management enables the client, developers, facilitators and other stakeholders related to the project to achieve value for money by implementing modern technologies within the Sri Lankan construction industry. The study also revealed that there is a high degree of agreement between the Quantity Surveyors, Architects, and Civil Engineers on the advantages 
gain by applying new technologies for the minimization of concrete waste in the Sri Lankan construction industry. Therefore, the above findings will make a momentum to the industry practitioners to re-think about the concrete waste which represents how much they can minimize the waste at site levels contributing to sustainability.

The first objective of this research was to recognize the sources of concrete waste in construction projects. Therefore, the first objective of this research was achieved with the usage of literature synthesis and primary data collection survey. Identifying the factors that affect concrete waste through literature synthesis and preliminary survey were also used to prepare the questionnaire survey. The findings of the questionnaire survey were set with the statistical package of social sciences (SPSS) software to find out the relationship (whether it impacts or not) between the sources of concrete waste and the project cost. The literature synthesis showed there are few instances adhere concrete waste occurs during both design and construction process. The questionnaire survey findings revealed that, design changes at the mid of the construction, poor coordination among the stakeholders, improperly identify the client's requirements, ordering of excess quantity, attitudes towards the construction operations and material handling at the design and construction stages be the sources, that generate concrete waste which will directly impact to the project cost. The analysis clearly illustrates that, there is a relationship of the sources of waste with the project cost.

The second objective of this research was to find out the contemporary practices in minimizing the concrete waste, achieved by both literature synthesis and primary data collection. According to the literature findings, there are few contemporary practices that are implemented by other countries currently as computer aided software (BIM), value engineering techniques, concrete recycling, use of precast and prefabrication elements in construction. The results of the questionnaire survey was subjected to the statistical data analysis method (SPSS), which shows the views on new practices and currently implementing practices within Sri Lanka by the construction professional who are currently engaging with the construction activities. According to those results, it was found that use of precast and prefabrication elements in construction, use as ready-mix concrete instead of cast in-situ concrete, implement value engineering techniques within the projects currently in Sri Lanka. These findings were used to discover the relationship between practicing of new practices and the project cost. After, analysing all data statistically it was found that there is a positive relationship, which to reduce the project cost.

Discovering the barriers to overcome the concrete waste is another objective of this research to fulfil. This objective was achieved with the support of the literature and the primary data collection.

Both literature and the empirical findings revealed that, lack of skilled labourers, negative attitudes towards new practices, resistance to change from the conventional practices are few of barriers. The statistical data analysis method used to evaluate the relationship which took a positive way, where the barriers also affect to reduce the project cost by minimizing concrete waste.

The final objective of this research is to recommend appropriate approaches to minimize concrete waste by reducing the project cost, which achieved while analysing the findings. According to the results, there were few drivers, which drives the attitudes of the stakeholders towards the practicing of these current techniques towards minimizing concrete waste, but at the same time the barriers lead to act as defensive way when implementing these practices. When considering their opinions, considerable amount is there willing to implement contemporary practices within their projects. In Sri Lanka as a developing country, can recommend use of ready-mix concrete (RMC), precast elements, value engineering techniques 
and few other practices as most appropriate techniques to minimize concrete waste towards reducing the project cost.

Define abbreviations and acronyms the first time they are used. Do not use abbreviations in the titles unless unavoidable.

\section{RECOMMENDATIONS AND IMPLICATIONS}

This study covered several aspects related to reduction of concrete waste using contemporary practices, which will be beneficial to reduce the project cost. Therefore, the following recommendations will assist in implementing those contemporary practices / systems in the Sri Lankan construction industry to minimize concrete waste.

Educating professionals and all other parties engaged in the construction industry about contemporary practices by; arranging training programs, rewarding the persons who are willing to use contemporary practices within their contracting organizations.

Applying lean construction, concrete recycling, use of precast concrete elements, value engineering techniques with regard to minimizing concrete wastage and also to reduce other types of material waste such as cement and reinforcements.

Encouraging cooperation between the clients and all the other stakeholder who are part of the construction activities in a particular project by applying new methods, use computer aided software such as BIM, which leads to build up the collaboration among the stakeholders in the project.

Changing the negative attitudes towards the implementation of new practices among the labourers and the other professionals related to construction, by providing proper guidance, and explaining the advantages that gaining to the project by minimizing concrete waste.

When considering the above-mentioned recommendations, it is necessary to imply these contemporary practices within the Sri Lankan construction industry that leads to reduce the project cost, and also benefited to move towards the sustainable developments through protecting the environment.

\section{LIMITATIONS}

Evaluated contemporary practices are only to minimize concrete waste that generates from the construction projects. Time, Cost and Quality are the primary three keys in the construction project. Therefore, among those keys, this research study was endeavoured to evaluate environmental and cost related concerns related to concrete waste reduction which yet controlled by the stakeholders.

\section{REFERENCES}

Anon., 2010. Advances in new concrete technology. [Online] Available from: https://www.aggregateresearch.com/news/advances-in-new-concrete technology

Dosho, Y., 2007. Development of a sustainable concrete waste recycling system: Application of recycled aggregate concrete produced by aggregate replacing method. Journal of Advanced Concrete Technology, 5(1), pp. 27-42.

Formoso, C., Soibelman, L. and De Cesare, C., 2002. Material Waste in Building Industry: Main Causes and Prevention. Journal of Construction Engineering and Management, 128(4), pp. 316-325.

Harris, F. and McCaffer, R., 2005. Modern Construction Managment. $5^{\text {th }}$ Ed. Accra: EPP Book Services.

Kazaz, A., Ulubeyli, S. and Turker, F., 2004. The quality perspective of the ready mixed concrete industry in Turkey. 39, pp. 1349-1357. 
Kulatunga, U., Amaratunga, D., Haigh, R. and Rameezdeen, R., 2006. Attitudes and perceptions of construction workforce on construction waste in Sri Lanka. Management of Environmental Quality: An International Journal, 17(1), pp. 57-72.

Richardson, A., Allain, P. and Veuille, M., 2010. Concrete with crushed, graded and washed recycled construction demolition waste as a coarse aggregate replacement. Structural Survey, 28(2), pp. 142-148.

Saunders, J. and Wynn, P., 2004. Attitudes towards waste minimization amongst labour only sub-contractors. Structural Survey, 32(3), p. 148-155.

Shen, L., Tam, V. and Li, C., 2008. Benefit analysis on replacing in situ concreting with precast slabs for temporary construction works in pursuing sustainable construction practice. Resources. Conservation and Recycling, 3, pp. 145-148.

Silva, R., de Brito, J. and Dhir, R., 2014. Properties and composition of recycled aggregates from construction. Construction and Building Materials, 65, pp. 201-217.

Treloar, G., Gupta, H., Love, P. and Nguyen, B., 2003. An analysis of factors influencing waste minimisation and use of recycled materials for the construction of residential buildings. Management of Environmental Quality. An International Journal, 14(1), pp. 134-145.

Zhen, C., Heng, L. and Wong, C., 2002. An application of bar-code system for reducing construction wastes. Automation in Construction, 11(5), pp. 521-533.

Zuhairi, Maria. and Ahmad, 2016. Sustainable construction waste management. The Ingenieur, 66, p. 70. 